\section{Identification of Indian Timbers}

Two leaflets have been issued by the Forest Research Institute.(Pub. Forest Research Inst., Dehra Dun), on "How to Identify Timbers", Nos. 21 and 25 (Utilisation). The present War, as was the case with the War of 1914-18, has made a great demand on the timber resources of India. As the demand increases, many new or little-known timbers are being placed on the market. Considerable confusion in identity has supervened, causing perfectly good timbers for the purpose in view to fall into disrepute owing to the substitution of inferior ones. This fact has become well understood by the Defence and Supply Departments which handle timbers, and many inquiries on the subject have been put to the Institute. Leaflet (Part 1) No. 21 gives some general information on the subject of identification of timbers, well known to students of the subject. Leaflet (Part 2) No. 25 is more specialized, dealing with the identification of timbers for "Helves and Tool Handles". The leaflet gives a key for the field identification of certain timbers for tools, the demand for which in ever-increasing numbers, as is well known, has become world-wide. Short anatomical descriptions of the timbers mentioned as suitable for the purpose are included.

\section{The High-pressure Gas-filled Cable}

$I_{N}$ a recent paper on this subject read by C.J. Beaver and E. L. Davey before the Institution of Electrical Engineers in London, the present position of existing types of high-voltage cables is briefly reviewed and the reasons underlying the development of the gasfilled cable are given. Following a brief description of the cakle, the design is dealt with in detail. The construction and manufacture of the cable are then deseribed and the physical behaviour of the cable in service is considered. Details of the accessories associated with the cable system are given, and the routine type and research testing of both cable and accessories are discussed. After dealing with gaspressure considerations of the cable system in service and installations carried out, a brief survey of the economic aspect of the cable is given.

It is concluded that the high-pressure gas-filled cable system has certain special advantages, and that since its technical and economic positions are sound it should, in the future, be a tactor to be taken into consideration when schemes involving power transmission at voltages of $33 \mathrm{kV}$. and upwards are envisaged. The design of the gas-filled cable is based upon a quantitative appreciation of the electrical and physical requirements of the dielectric of a cable to withstand service conditions without deterioration, and definite margins of safety are provided and maintained. The manufacture of the cable does not involve the use of any novel or special plant or manufacturing processes other than those which have already been in use for many years past in the manufacture of the solid-type cable. The cable system is free from external accessories, and no special arrangement is necessary if the cable is run vertically for any height or distance. The economic aspect of the cable for the voltage range of $33-132 \mathrm{kV}$. is good. 'The permittivity of the dielectric is a good deal lower than that of any other impregnated-paper dielectric. This is of importance in relation to the future use of higher voltage and more highly stressed cables, and the necessity of keeping the cable capacitance load on systems to a minimum value.

\section{Earthquakes Registered at Kew}

During April 1943, seven strong earthquakes were registered by the seismographs at Kew Observatory. The first of these, on April 1, was registered at $14 \mathrm{~h}$. $4 \mathrm{~lm}$. 40s. U.T., and a tentative analysis puts the epicentre $15,000 \mathrm{~km}$. distant. The maximum ground amplitude at Kew due to this shock was $115 \mu$. The second shock was on April 5. This earthquake, from an epicentre some $5,450 \mathrm{~km}$. distant, recorded $e P z$ at Kew at $02 \mathrm{~h} .05 \mathrm{~m} .09 \mathrm{~s}$. U.T. and attained a maximum ground amplitude at Kew of $67 \mu$ at $02 \mathrm{~h} .25 \mathrm{~m} .18 \mathrm{~s}$. U.T. The third shock was on April 6, recording impulsively on the vertical component at $16 \mathrm{~h}$. $21 \mathrm{~m}$. 10s. U.T. It attained a maximum ground amplitude at Kew of $470 \mu$ on the east-west component at $17 \mathrm{~h}$. $05 \mathrm{~m}$. 35s. U.T. It came from an epicentre some $11,450 \mathrm{~km}$. distant, the epicentre possibly being in the neighbourhood of lat. $30^{\circ} \mathrm{S}$., long. $70^{\circ} \mathrm{W}$., which is in Chile. On this day a message from Santiago de ( hile said that a very severe earthquake with epicentre in the Illapel zone had partly destroyed buildings in Illapel, La Serena, Combarbala and Ovalle. Further details were not given as communications with the area were severed. The fourth shock, on April 7, recorded $e P$ on all three components at $09 \mathrm{~h} .03 \mathrm{~m} .40 \mathrm{~s}$. U.T. and a tentative analysis puts the epicentral distance at some $11,500 \mathrm{~km}$. The fifth earthquake, on April 11, recorded iP on all three components at $14 \mathrm{~h} .58 \mathrm{~m}$. $43 \mathrm{~s}$. U.T. from an epicentre some $9,100 \mathrm{~km}$. distant. Maximum ground amplitude at Kew was $170 \mu$ on the vertical component at $15 \mathrm{~h}$. 4Im. 17s. U.T. The sixth earthquake came from I,800 km. away and therefore may be considered a near shock. On April 16 it recorded $i P z$ at $1 \mathrm{lh}$. $76 \mathrm{~m}$. 56s. U.T. and finished recording near $12 \mathrm{~h}$. $25 \mathrm{~m}$. The seventh and last strong shock of the month was recorded on April 29. It began recording with iP on the vertical and north-south components at $15 \mathrm{~h}$. $37 \mathrm{~m}$. 05s. U.T. and came from an epicentre some $8,800 \mathrm{~km}$. distant.

\section{Earthquake in Colombia}

The United States Coast and Geodetic Survey, in co-operation with Science Service and the Jesuit Seismological Association, has received instrumental reports concerning an earthquake on December 26 from the observatories at St. Louis, Georgetown, San Juan, Tucson, Fordham, Philadelphia, Des Moines and Huancayo. From this data it appears that the earthquake originated at approximately $12 \mathrm{~h} .31 \cdot 8 \mathrm{~m}$. U.T. from an epicentre near latitude $9 \cdot 0^{\circ} \mathrm{N}$., longitude $75 \cdot 0^{\circ} \mathrm{W}$. This is in Colombia, South America, near the confluence of the Cauca and Magdalena Rivers. Earthquakes are not uncommon in this region.

\section{Supply of Organic Compounds}

WE have received from L. Light and Co., Ltd., Old Bowry Laboratories, Wraysbury, Bucks, a price list of more than four hundred organic compounds not usually available commercially. This includes a large number of compounds used in synthetic work, such as ethyl acetoacetate, ethyl malonate, and ethyl iodide, many alcohols, esters and ketones, and also inorganic reagents such as magnesium turnings, hydrazine, selenium, and selenium dioxide. It is very interesting to find that such a wide range of materials is available, and research workers should be materially assisted by having them at their disposal. A copy of the list can be obtained on application to the firm. 